06

\title{
Возможности энергонасыщенных композитов на основе нанопористого кремния (обзор и новые результаты)
}

\author{
( Г.Г. Савенков, ${ }^{1}$ А.Г. Зегря, ${ }^{2}$ Г.Г. Зегря, ${ }^{2}$ Б.В. Румянцев, ${ }^{2}$ А.Б. Синани, ${ }^{2}$ Ю.М. Михайлов ${ }^{3}$ \\ ${ }^{1}$ Санкт-Петербургский государственный технологический институт (технический университет), \\ 190013 Санкт-Петербург, Россия \\ ${ }^{2}$ Физико-технический институт им. А.Ф. Иофффе РАН, \\ 194021 Санкт-Петербург, Россия \\ ${ }^{3}$ Институт проблем химической фризики РАН, \\ 142432 Черноголовка, Россия \\ e-mail: sav-georgij@yandex.ru
}

(Поступило в Редакцию 11 июля 2018 г.)

\begin{abstract}
Представлены краткий обзор и результаты экспериментов по исследованию свойств энергонасыщенных композитов на основе нанопористого кремния. Рассмотрены различные типы окислителей, применяемые в композитах. В качестве окислителя использовался перхлорат кальция. Показано, что исследованный энергокомпозит по ряду параметров превосходит инициирующее взрывчатое вещество - гремучую ртуть и бризантное взрывчатое вещество - гексоген.
\end{abstract}

DOI: $10.21883 / J T F .2019 .03 .47175 .271-18$

\section{Вещество}

В последние годы большое внимание исследователей и практиков уделяется нанопористому кремнию, который был известен достаточно давно с момента публикации работы Улира в 1956 г. [1]. В настоящей работе пористый кремний получен в ходе исследований процесса электрохимической полировки поверхности кремния в водных растворах плавиковой кислоты HF. В настоящее время полагают, что пористый кремний является перспективным материалом микро-, нано- и оптоэлектроники. Его уникальные свойства легли в основу его использования для диагностики и лечения широкого спектра заболеваний [2]. В работе [3] рассматриваются более 15 научно-практических направлений, в которых с успехом может быть применен нанопористый кремний.

В настоящей работе рассматривается применение нанопористого кремния с точки зрения его энергетических свойств. Дело в том, что он может гореть в чистом виде, а в сочетании с определенными окислителями у него появляется способность к взрыву (детонации) [4]. Отметим, что в течение XX в. основными (традиционными) инициирующими взрывчатыми веществами (ИВВ), используемыми для снаряжения капсюлей-детонаторов (КД) и электродетонаторов (ЭД), были азид свинца $\mathrm{Pb}\left(\mathrm{N}_{3}\right)_{2}$ и гремучая ртуть $\left(\mathrm{Hg}(\mathrm{CNO})_{2}\right)$. Ограниченно в некоторых средствах инициирования (СИ) применялись азид серебра $\left(\mathrm{AgN}_{3}\right)$, азид кадмия $\left(\mathrm{Cd}\left(\mathrm{N}_{3}\right)_{2}\right)$ и азид таллия $\left(\mathrm{TIN}_{3}\right)$. В воспламенительных составах применялись и применяются так называемые псевдоинициирующие взрывчатые вещества - стифнат свинца (ТНРС) и тетразен. Псевдоинициирующие ВВ обладают, так же как и традиционные ИВВ высокой чувствительностью к внешним воздействиям, но при этом период нарастания скорости взрывчатого превращения у них слишком велик, что приводит к слабой инициирующей способности.

В настоящее время гремучая ртуть повсеместно запрещена к применению в промышленных средствах инициирования из-за ее чрезвычайной токсичности $[5,6]$. Традиционные ИВВ позволяют создать средства инициирования, удовлетворяющие в основном требованиям промышленности и военной техники по надежности, взрывчатым и эксплуатационным характеристикам.

Однако использование десятков миллионов КД и ЭД привело к тому, что сотни килограммов суперэкотоксиканта свинца попадают ежегодно в окружающую среду, нанося вред как экосистемам, так и персоналу. Как известно, свинец входит наряду с кадмием и ртутью в состав „мрачной тройки“ наиболее токсичных промышленных цветных металлов [7]. Поэтому разработка энергетических материалов в качестве ИВВ и инициирующих взрывчатых составов (ИВС) с повышенными экологическими свойствами (так называемые „зеленые“ ИВВ и ИВС) стоит на повестке дня у всех промышленно развитых стран. Отметим, что под ИВС в настоящей работе понимаются именно инициирующие взрывчатые составы, а не воспламенительные составы, которые хотя и содержат ИВВ, но предназначены для капсюлейвоспламенителей. И, кроме того, мы не будем рассматривать так называемые псевдоинициирующие взрывчатые вещества (например, стифнат свинца, тетразен, тетразол), которые, как и классические ИВВ, обладают повышенной чувствительностью к простым внешним воздействиям. Однако при этом период нарастания скорости взрывчатого превращения у них слишком велик и вследствие этого они не обладают достаточной инициирующей способностью в нормальных условиях.

В этом плане в качестве альтернативы классическим ИВВ заслуживают внимание энергонасыщенные компо- 
зиты на основе нанопористого кремния, первые сведения о которых в качестве ИВС появились сравнительно недавно [8-13]. Кроме того, как будет показано ниже, такие композиты могут конкурировать и с бризантными взрывчатыми веществами. Можно отметить, что нанопористый кремний, помимо применения во взрывной энергетике, материал с широким спектром потенциальных применений, в том числе в катализе, фотонике, электрохимических приложениях и др.

\section{Краткий обзор}

То, что при определенных условиях в присутствии окислителя пористый кремний имеет тенденцию к воспламенению, горению и даже к детонации при механических, электрических и термических воздействиях впервые было отмечено еще в 1992 г. Р. Mc Cord, S.-L. Yau and A.J. Bard [8].

Первая серьезная работа по изучению процессов горения и взрыва в пористом кремнии была проведена Д. Ковалевым и В.И. Тимошенко с соавторами [9]. В этой работе авторы сообщили о наблюдении взрывных реакций даже при криогенных температурах, когда пористый кремний погружался в жидкий кислород.

В докладе [10] впервые была предложена конструкция пиропатрона с энергонасыщенными композитами (ЭНК) на основе нанопористого кремния, предназначенного для срабатывания подушек безопасности в автомобилях. Поскольку нанопористый кремний является горючим, то в качестве окислителя в данной работе были предложены различные перхлораты: $\mathrm{KClO}_{4}, \mathrm{NH}_{4} \mathrm{ClO}_{4}$, и $\mathrm{RbClO}_{4}$. Были получены обнадеживающие результаты, которые позволили авторам предположить, что при надлежащем подборе окислителя можно получить работоспособную конструкцию пиропатрона, в которой будет отсутствовать в качестве ИВВ азид свинца.

В работах $[11,12]$ были рассмотрены энергокомпозиты (ЭНК) на основе нанопористого кремния, в качестве окислителей в которых использовались как перхлораты, так и бризантные взрывчатые вещества (БВВ) ТЭН, гексанитростельбен и сравнительно новое ВВ нитриминотетразол $\left(\mathrm{CH}_{2} \mathrm{~N}_{6} \mathrm{O}_{2}\right)$, а также псевдоинициирующее ВВ - тетразол. Авторы утверждали, что с применением ЭНК на основе нанопористого кремния и нитриминотетразола им удалось создать детонатор для надежного инициирования взрывчатого состава на основе гексогена (RDX) и полимерного связующего.

B качестве окислителей, кроме уже вышеупомянутых, применялись также тригидрат перхлората лития $\left(\mathrm{LiClO}_{4} \cdot 3 \mathrm{H}_{2} \mathrm{O}\right)$, тетрагидрат нитрата кальция $\left(\mathrm{Ca}\left(\mathrm{NO}_{3}\right)_{2} \cdot 4 \mathrm{H}_{2} \mathrm{O}\right)$, тригидрат нитрата лития $\left(\mathrm{LiNO}_{3} \cdot 3 \mathrm{H}_{2} \mathrm{O}\right)$, хлорная кислота $\left(\mathrm{HClO}_{4}\right)$, сера [14], тетрагидрат нитрата марганца $\left(\mathrm{Mn}\left(\mathrm{NO}_{3}\right)_{2} \cdot 4 \mathrm{H}_{2} \mathrm{O}\right)$, гидрат нитрата гадолиния $\left(\mathrm{Gd}\left(\mathrm{NO}_{3}\right)_{3} \cdot x \mathrm{H}_{2} \mathrm{O}\right)(x \approx 6)$, гексагидрат нитрата магния $\left(\mathrm{Mg}\left(\mathrm{NO}_{3}\right)_{2} \cdot 6 \mathrm{H}_{2} \mathrm{O}\right)$ и пятиокись иода $\left(\mathrm{I}_{2} \mathrm{O}_{5}\right)$ [15].
Полагают, что наиболее эффективными окислителями являются перхлораты, так как они имеют высокое содержание кислорода и относительно стабильны по сравнению с другими окислителями, а наиболее оптимальный из них перхлорат натрия [14]. Теплота взрыва ЭНК на основе нанопористого кремния с перхлоратом натрия $-20 \mathrm{~kJ} / \mathrm{g}$ [15]. Однако большинство перхлоратов гигроскопичны, а негигроскопичные перхлораты калия и рубидия не растворимы в обычных растворителях. Малогигроскопичный перхлорат аммония после испарения растворителя выдавливается из пор кремния на поверхность. По скорости горения неплохие результаты показал ЭНК с тетрагидратом нитрата марганца $(\sim 28 \mathrm{~m} / \mathrm{s})[15]$, при этом его теплота взрыва $-12.5 \mathrm{~kJ} / \mathrm{g}$. Одной из основных проблем при создании ЭНК на основе нанопористого кремния является определение точного количества окислителя, необходимого для высокоэнтальпийной экзотермической реакции с горючим.

Результаты, полученные в работе [13], свидетельствовали о высокой активности наноструктурированной поверхности пористого кремния по отношению к окислителям, площади удельной поверхности и содержанию водорода. Это проявляется в чрезвычайно высоком уровне чувствительности к удару бинарных систем на основе пористого кремния и окислителя, которые содержали всего 4 wt.\% перхлората кальция. По мнению авторов, высокая активность поверхности наноструктурированного пористого кремния, по-видимому, еще в большей степени может проявиться по мере приближения состава бинарной системы к стехиометрическому соотношению компонентов.

В принципе, в настоящее время в патентной литературе приводится достаточно большой ряд патентов на создание ЭНК на основе нанопористого кремния и окислителя. Так, например, в патенте США № 6984274 [16] описан ЭНК на основе нанопористого кремния в качестве горючего и в качестве окислителя (как пример) - гидрид калия (КН). При этом, как это часто случается в патентах, в качестве окислителей была заявлена большая группа соединений, а нанопористый кремний имел чрезвычайно широкий диапазон размера пор $(2-1000 \mathrm{~nm})$, справедливости ради авторы уточняют, что предпочтительнее размеры пор от 2 до $200 \mathrm{~nm}$. Пористость патентованного ЭНК также лежит в широком диапазоне: от 10 до 98\%. Взрыв инициируется электрической искрой, теплота взрыва $-28 \mathrm{~kJ} / \mathrm{g}$ (теоретическая).

В патенте США № 6803244 [17] в качестве окислителя предлагается использовать нитрат лития $\left(\mathrm{LiNO}_{3}\right)$, который, также как и перхлораты, является гигроскопичным веществом. Получаемый по данному патенту ЭНК (nanopor $\mathrm{Si}+\mathrm{LiNO}_{3}$ ) по утверждению авторов имеет очень высокие энергетические свойства: температура взрыва - $12000 \mathrm{~K}$, скорость горения - $104 \mathrm{~m} / \mathrm{s}$, плотность энергии (теплота взрыва, также как и в предыдущем патенте, очень высока) - $28 \mathrm{~kJ} / \mathrm{g}$. Можно отметить, 
что теплота взрыва большинства мощных бризантных ВВ не превосходит $8 \mathrm{~kJ} / \mathrm{g}[18]$.

В работе [19] проведено исследование возбуждения взрывчатых превращений в нанопористом кремнии, пропитанном либо раствором перхлората кальция $\left(\mathrm{Ca}\left(\mathrm{ClO}_{4}\right)_{2}\right)$, играющего роль окислителя, либо раствором октогена, при помощи электрического взрыва полупроводника. В зависимости от уровня давления и температуры в исследованных энергетических соединениях (ЭС) возникали режимы взрывчатого превращения - горение или низкоскоростная детонация.

Кроме использования ЭНК на основе нанопористого кремния в качестве ИВВ в работах $[19,20]$ рассматривалась возможность их применения и в качестве бризантного ВВ. Высокое энергетическое поведение рассмотренных энергокомпозитов обычно связывают с очень высокой удельной поверхностью области соприкосновения горючего (кремний) и окислителя, что и приводит к чрезвычайно быстрой реакции [21]. Дополнительным преимуществом ЭНК на основе нанопористого кремния $\mathrm{Si}$ по сравнению, например, с энергокомпозитами на основе наноразмерного алюминия является его большая устойчивость к инициированию электростатическим разрядом (что является основным препятствием для широкого использования нанотермитов на основе наноалюминия) [22].

Отмечается, что наиболее важным в развитии технологии энергокомпозитов на основе нанопористого кремния являются такие аспекты, как тип используемого окислителя, стабилизация окислителя в порах, влияние поверхностного водорода на долговременную стабильность и энергетические свойства энергокомпозита [23].

Как следует из недавней обзорной монографии [14], несмотря на достаточно большое количество работ, посвященных ЭНК на основе нанопористого кремния, в них достаточно мало уделяется вопросу влияния размера нанопор и доле окислителя на взрывчатые свойства получаемых ЭНК.

\section{Новые результаты}

Настоящий раздел посвящен исследованию взрывных возможностей ЭНК на основе нанопористого кремния и перхлората кальция в качестве окислителя. Эти исследования в некоторой степени устраняют указанное невнимание к вышеназванным параметрам ЭНК.

\section{Энергонасыщенный композит, технология его получения, инициирующее взрывчатое вещество и методики исследований}

В качестве горючего в ЭНК использовался нанопористый кремний, который получали двусторонним электрохимическим травлением пластин монокристаллического кремния марки КДБ-100, легированных бором, с концентрацией носителей заряда $\sim 10^{19} \mathrm{~cm}^{-3}$, в

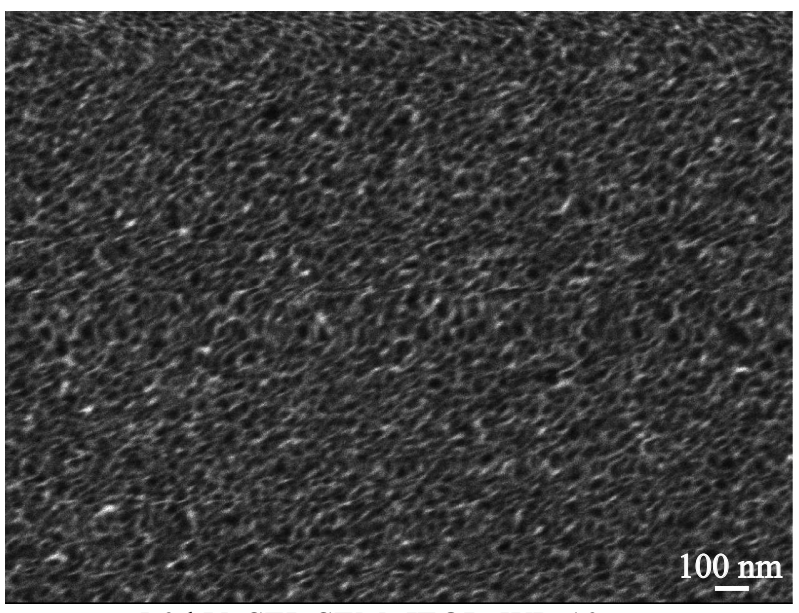

$5.0 \mathrm{kV}$ SEI SEM JEOL WD $10 \mathrm{~mm}$

Рис. 1. СЭМ-изображение поверхности образца нанопористого кремния.

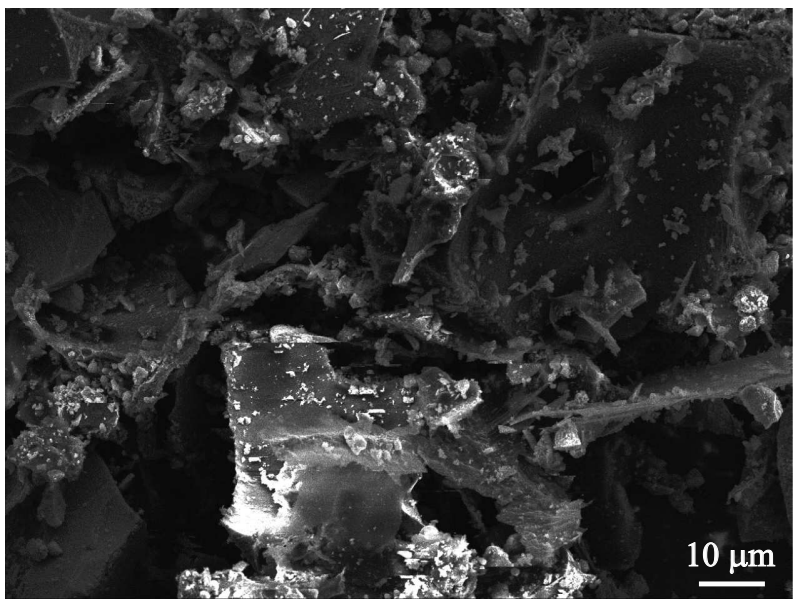

$\times 1.0005 .0 \mathrm{kV}$ SEI SEM JEOL WD $10 \mathrm{~mm} \mathrm{06/14/18}$

Рис. 2. СЭМ-изображение частиц порошка нанопористого кремния.

HF-содержащем электролите, состоящем из плавиковой кислоты (40 wt.\%) и метанола в соотношении 1:1. Травление осуществляли при плотностях тока около $100 \mathrm{~mA} \mathrm{~cm}^{-2}$ в течение 50-60 min для формирования нанопористых кремниевых слоев толщиной $\sim 200 \mu \mathrm{m}$.

На рис. 1, полученном с помощью сканирующей электронной микроскопии (СЭМ), приведена морфология поверхности нанопористой пластины.

Пластины вручную измельчали в ступке, просеивали через сито с размерами ячеек $40 \times 40 \mu \mathrm{m}$. По такой технологии получали порошок нанопористого кремния с размером частиц 30-40 $\mu \mathrm{m}$. При диспергировании пластин часть стенок пор разрушилась, и в результате образовывалось какое-то количество пор более крупных размеров (субмикронных или даже микронных). Полученный порошок представлен на СЭМ-изображении рис. 2. 
Таблица 1. Структурные параметры образцов КДБ-100

\begin{tabular}{c|c|c|c|c|c}
\hline Образец & $S, \mathrm{~m}^{2} / \mathrm{g}$ & $V_{\Sigma}, \mathrm{cm}^{3} / \mathrm{g}$ & $\langle d\rangle, \mathrm{nm}$ & $\rho, \mathrm{g} / \mathrm{cm}^{3}$ & $P, \%$ \\
\hline КДБ-100-1 & 321 & 0.98 & 12.2 & 0.72 & 70.4 \\
КДБ-100-2 & 333 & 1.32 & 15.8 & 0.58 & 76.2 \\
КДБ-100-3 & 368 & 1.92 & 20.9 & 0.43 & 82.3 \\
КДБ-100-4 & 366 & 1.97 & 21.5 & 0.42 & 82.7
\end{tabular}

Примечание. $S-$ удельная площадь поверхности, $V_{\Sigma}-$ суммарный объем пор, $\langle d\rangle-$ средний диаметр пор, $\rho-$ кажущаяся плотность, $P$ - степень пористости.

Параметры образцов пластин (размер пор, удельная поверхность, плотность и др.), применявшихся в экспериментах, приведены в табл. 1 .

Поскольку перхлорат-ион обладает достаточно высоким окислительным потенциалом, то в качестве окислителя для формирования исследуемых композитов был выбран, несмотря на его гигроскопичность, перхлорат кальция $\left(\mathrm{Ca}\left(\mathrm{ClO}_{4}\right)_{2}\right)$. При выборе окислителя в основном учитывалось то, что максимальная растворимость перхлората кальция в метаноле позволяет по-

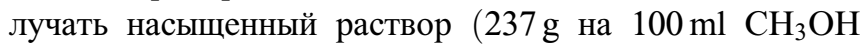
или $\sim 10 \mathrm{M})$, благодаря чему возможно практически полное заполнение объема пор кремния выбранным окислителем.

При этом раствор перхлората кальция в метаноле технологически удобен, поскольку метанол легко удаляется из пор за счет его интенсивного испарения и из него можно высадить кристаллический (твердый) окислитель. Энергонасыщенные композиты запрессовывались в колпачок диаметром с внешним диаметром $d_{s}=8.0 \mathrm{~mm}$, высота запрессованного заряда ЭНК составляла $2 \mathrm{~mm}$.

Для сравнения ударно-волно вого воздействия от взрыва композитов на основе наноструктурированного пористого кремния с ударно-волновым воздействием от взрыва хорошо известных ВВ были проведены измерения с использованием инициирующего взрывчатого вещества (ИВВ $)$ - гремучей ртути $\left[\mathrm{Hg}(\mathrm{CNO})_{2}\right] .40 \mathrm{mg}$ $\mathrm{Hg}(\mathrm{CNO})_{2}$ запрессовывались в колпачки с внешним диаметром $6.4 \mathrm{~mm}$.

Известно [18], что, как и в любом другом классическом ИВВ, участок перехода горения в детонацию в зарядах из гремучей ртути очень мал, поэтому можно с уверенностью полагать, что в нашем случае при инициировании заряда $\mathrm{Hg}(\mathrm{CNO})_{2}$ происходил взрыв.

Количественное определение параметров взрывного процесса в исследованных ЭНК проведено с использованием тензометрических датчиков по методу мерных стержней, являющемуся полным аналогом метода Кольского с применением разрезного стержня Гопкинсона [24]. Инициирование реакции в образцах композитов на основе наноструктурированного пористого кремния, заключенных в тонкостенные алюминиевые капсулы и пропитанных через отверстия в них раствором окислителя, осуществлялось постепенным нагревом нихромового

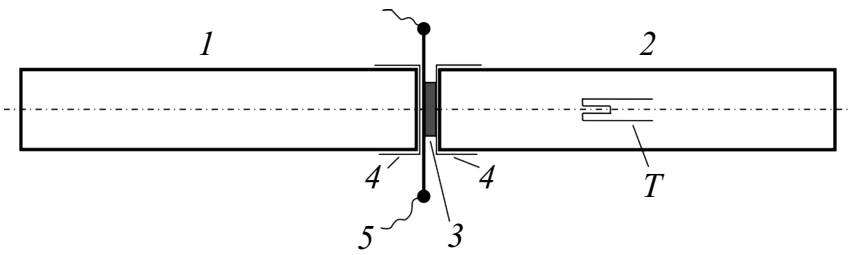

Рис. 3. Схема проведения эксперимента: 1 - опорный стержень $(d=8 \mathrm{~mm}) ; 2$ - измерительный стержень с тензометрическим датчиком $T(d=8 \mathrm{~mm}) ; 3$ - образец; 4 фторопластовая пленка толщиной $100 \mu \mathrm{m} ; 5-$ нихромовая фольга (тепловой инициатор).

фольгового мостика. Схема экспериментов показана на рис. 3.

Расчет амплитуды механических напряжений, сопровождающих вызванную взрывом волну деформаций в стержне, производился по формуле

$$
\sigma=\frac{\Delta U E S_{1}}{I R_{0} k S_{0}}
$$

где $\Delta U-$ импульс напряжения на осциллограмме, $I=15 \mathrm{~mA}$ - ток в тензодатчиках; $R_{0}=200 \Omega-$ сопротивление тензометров, $E=200 \mathrm{GPa}$ - модуль Юнга материала ИС и ОС (закаленные стали); $k=2$ коэффициент тензочувствительности; $S_{1}$ - площадь сечения измерительного стержня; $S_{0}-$ площадь торцевой поверхности образца.

Кроме вышеописанной методики с использованием мерного стержня в работе была применена методика, позволяющая сравнить заряды из ЭНК массой $1.2 \mathrm{~g}$ (с равным количеством горючего и окислителя $\left.\left(\mathrm{Ca}\left(\mathrm{ClO}_{4}\right)_{2}\right)\right)$ и RDX массой $1.2 \mathrm{~g}$, который инициировался ИВВ массой $0.35 \mathrm{~g}$. Диаметр обоих зарядов составлял $d=20 \mathrm{~mm}$, высота - $3 \mathrm{~mm}$. Заряды устанавливались на диски из дюралюминиевого сплава Д16Т диаметром $112 \mathrm{~mm}$ и толщиной $h=4 \mathrm{~mm}$. Инициирование зарядов осуществлялось с помощью нагреваемой электрическим током стальной пластины, диаметр которой превышал диаметр заряда. Сверху на пластину устанавливалась массивная плита, что позволяло направлять всю энергию взрыва зарядов на дюралюминиевые диски.

\section{Результаты экспериментальных исследований}

Эксперименты с применением мерных стержней

На рис. 4 приведена осциллограмма (избавленная от всех шумов) импульсов напряжений в мерном стержне при взрыве $40 \mathrm{mg}$ гремучей ртути. Величина импульса напряжения $\Delta U$ составила $2.5 \mathrm{mV}$ при длительности импульса на полувысоте $20 \mu \mathrm{s}$. Соответствующее расчетное значение механического напряжения $\sigma=130 \mathrm{MPa}$.

При инициировании заряда из ЭНК $\left(n-\mathrm{Si}+\mathrm{Ca}\left(\mathrm{ClO}_{4}\right)_{2}\right)$ общей массой $40 \mathrm{mg}$ величина импульса напряжения $\Delta U$ составила $6.0 \mathrm{mV}$ при длительности импульса на полувысоте $4.0 \mu \mathrm{s}$ (рис. 5). Соответствующее расчетное 
Таблица 2. Параметры взрывных процессов в образцах КДБ-100

\begin{tabular}{c|c|c|c|c|c|l}
\hline Образец & $\begin{array}{c}m_{\mathrm{Si}}, \\
\mathrm{mg}\end{array}$ & $\begin{array}{c}m, \\
\mathrm{mg}\end{array}$ & $\begin{array}{c}\Delta U, \\
\mathrm{mV}\end{array}$ & $\begin{array}{c}\sigma, \\
\mathrm{MPa}\end{array}$ & $\begin{array}{c}\tau, \\
\mu \mathrm{s}\end{array}$ & $\begin{array}{l}P, \\
\mathrm{Ns}\end{array}$ \\
\hline КДБ-100-1 & 17 & 55 & 12 & 400 & 6 & 0.15 \\
КДБ-100-2 & 15 & 60 & 14 & 470 & 8 & 0.235 \\
КДБ-100-3 & 12 & 50 & 10 & 335 & 5 & 0.105 \\
КДБ-100-4 & 10 & 40 & 6 & 200 & 4 & 0.05 \\
$\mathrm{Hg}(\mathrm{CNO})_{2}$ & - & 40 & 2.5 & 130 & 20 & 0.084
\end{tabular}

Примечание. $m_{\mathrm{Si}}-$ исходная навеска пористого кремния; $m$ - масса композита; $\Delta U-$ амплитуда импульса напряжения; $\Sigma$ - амплитуда импульса механического напряжения; $\tau$ - длительность импульса.

значение механического напряжения $\sigma=200 \mathrm{MPa,} \mathrm{т.} \mathrm{е.} \mathrm{в}$ этом случае наблюдается увеличение общего импульса взрыва при уменьшении его длительности.

В табл. 2 приведены параметры зарядов из гремучей ртути и ЭНК на основе образцов КДБ-100, структурные характеристики которых представлены в табл. 1, а также значения их амплитуд механических напряжений. Кроме того, в этой же таблице для каждого из исследуемого заряда приведены значения механического импульса, рассчитанные по соотношению $P=\sigma S_{0} \tau$.

Как следует из представленных результатов, во всех случаях амплитуда импульса механического напряжения при взрывчатом превращении зарядов КДБ была существенно выше, чем при взрыве заряда из гремучей ртути. Таким образом, можно сделать вывод о том, что при взрывчатом превращении зарядов КДБ наблюдался режим нестационарной детонации (режим нормальной детонации, учитывая очень малые навески зарядов, маловероятен). При этом следует отметить, что скорость нарастания давления до максимального значения у зарядов КДБ существенно выше, чем у заряда из $\mathrm{Hg}(\mathrm{CNO})_{2}$.

\section{Эксперименты с дюралюминиевыми дисками}

На рис. 6 приведены фотографии дисков в исходном состоянии и после подрыва зарядов из КДБ и $\mathrm{RDX}$ (гексогена).

Диаметр пробитых отверстий: $D_{1}=78 \mathrm{~mm}$ (рис. $\left.6, b\right)$, $D_{2}=47 \mathrm{~mm}$ (рис. $\left.6, c\right)$. Полученные результаты по пробитию дисков позволяют провести оценку соотношения между импульсами взрыва обоих зарядов.

Схема, принятая для расчета импульсов взрыва, представлена на рис. 7.

Вследствие фрагментации выбитой части диска полагаем, что вся энергия активной массы заряда (в качестве допущения принимаем, что активные массы зарядов равны) пошла только на отделение и разрушение этой части (пренебрегаем скоростью фрагментов). При принятом допущении импульс взрыва определяется соот-

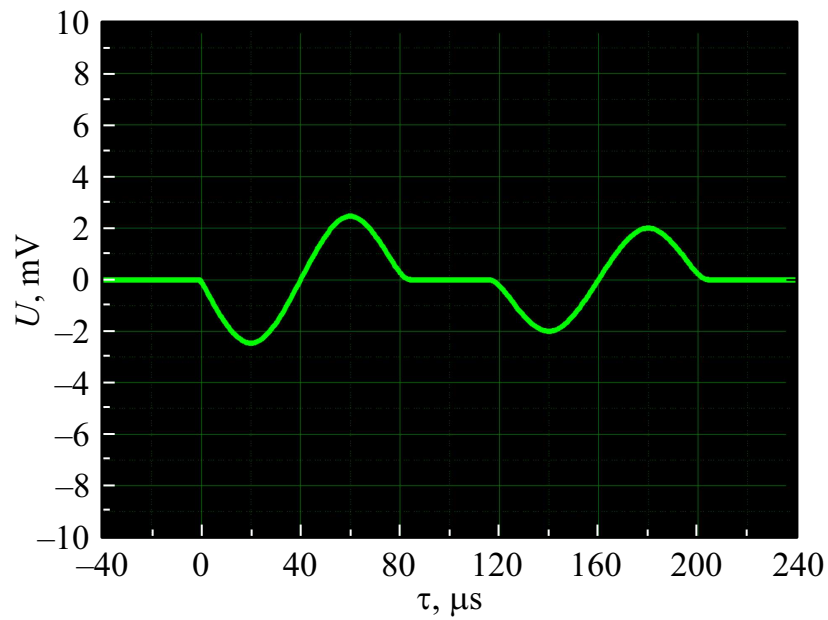

Рис. 4. Осциллограмма импульса деформации, зафиксированная в измерительном стальном стержне после взрыва $40 \mathrm{mg}$ гремучей ртути.

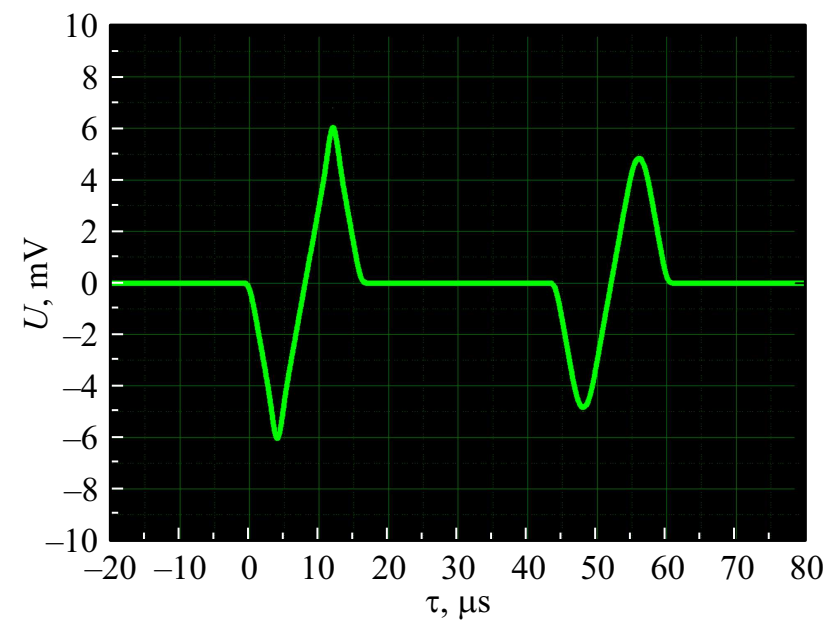

Рис. 5. Осциллограмма импульса деформации, зафиксированная в измерительном стальном стержне после взрыва $40 \mathrm{mg}$ ЭНК.

ношением [25]

$$
J=\theta \alpha \sqrt{2 M \Lambda_{f}},
$$

где $\theta$ - коэффициент, учитывающий дисперсию скоростей фрагментов; $\alpha-$ коэффициент, учитывающий дополнительные потери энергии взрыва на образование трещин в невыбитой части диска и ее изгиб; $M-$ масса отделившейся (выбитой) части диска; $\Lambda_{f}-$ энергия разрушения материала диска.

Под величиной энергии разрушения будем понимать значение интеграла

$$
\Lambda_{f}=\int_{S} \lambda_{f} d S,
$$

где $\lambda_{f}$ - удельная энергия разрушения; $S=\frac{\pi}{4} D_{i}^{2}-$ площадь разрушения. При постоянной площади соотно- 

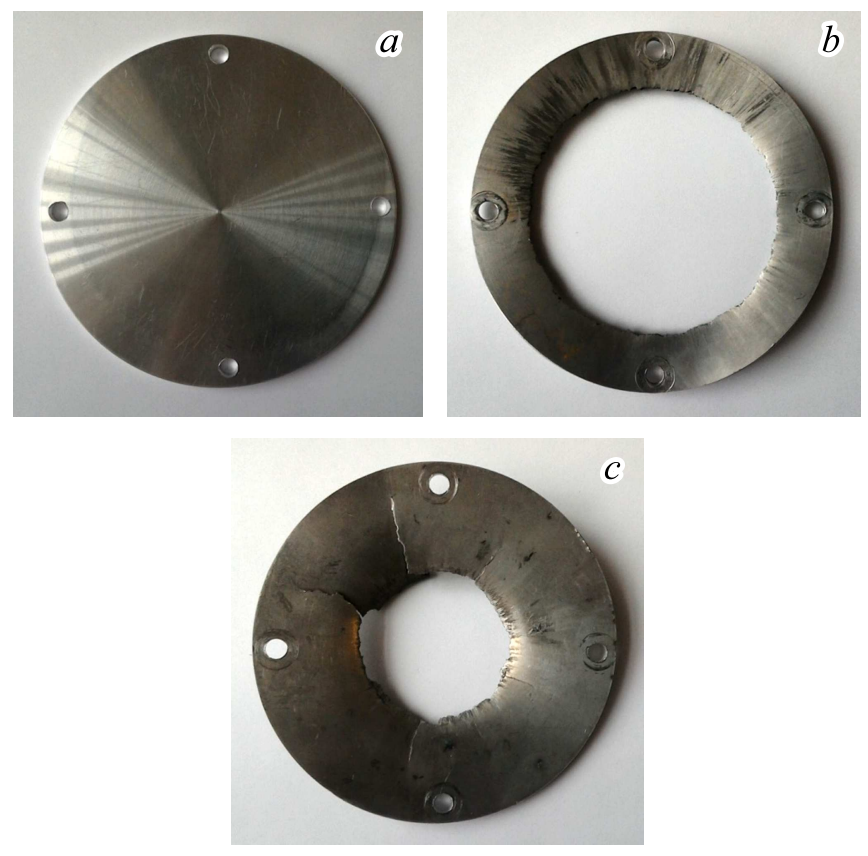

Pис. 6. Общий вид разрушенных дисков: $a-$ исходный диск; $b$ - диск, разрушенный энергонасыщенным зарядом КДБ; $c-$ диск, разрушенный зарядом RDX.

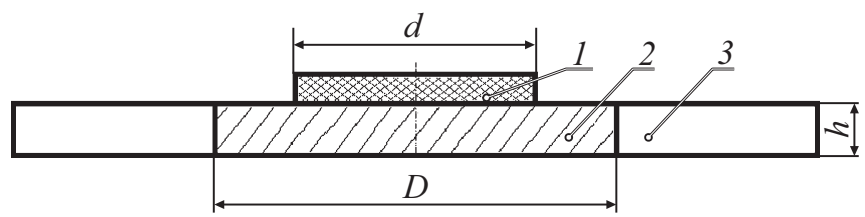

Рис. 7. Схема разрушения диска: $1-$ энергонасыщенный композит на основе наноструктурированного пористого кремния или заряд RDX; 2 - диск из дюралюминия марки Д16Т; 3 область разрушения диска; $d-$ диаметр заряда; $h-$ толщина диска из дюралюминия марки Д16Т.

шение (2) примет вид

$$
\Lambda_{f}=\lambda_{f} \pi D_{i}^{2} / 4
$$

После подстановки (3) в (1) с учетом значения отделившейся массы получим следующее выражение для определения импульса взрыва через свойства и геометрию выбитой части:

$$
J_{i}=\frac{\pi}{4} D_{i}^{2} \theta_{i} \alpha_{i} \sqrt{2 h \rho \lambda_{f}},
$$

где $\rho$ - плотность материала диска.

Примем $\theta_{1}=\theta_{2}, \alpha_{1}=1, \alpha_{2}=1.4$, тогда после подстановки соответствующих значений в соотношение (4) получим

$$
\frac{J_{1}}{J_{2}}=\frac{D_{1}^{2}}{1.4 D_{2}^{2}}=1.97 .
$$

Таким образом, исследованный энергонасыщенный композит в рамках проведенных экспериментов существенно превосходит по энергетическим параметрам классическое бризантное взрывчатое вещество гексоген (RDX).

B связи с таким выводом было интересно определить расчетным путем тепловой эффект (теплоту взрыва) реакции $\mathrm{Si}+\mathrm{Ca}\left(\mathrm{ClO}_{4}\right)_{2}$, хотя авторы и полагают, что классические расчеты к композиту на основе нанопористого кремния неприменимы (отметим, что такие расчеты проводили и другие исследователи). Расчеты теплового эффекта проводились в рамках стандартной вычислительной программы АСТРА-4, разработанной в МГТУ им. Н.Э. Баумана. Для реакции

$$
\mathrm{Si}+\mathrm{Ca}\left(\mathrm{ClO}_{4}\right)_{2}=\mathrm{SiO}_{2}+\mathrm{CaCl}_{2}+3 \mathrm{O}_{2}
$$

тепловой эффект $Q=3.3 \mathrm{MJ} / \mathrm{kg}$. Для стехиометрической реакции

$$
4 \mathrm{Si}+\mathrm{Ca}\left(\mathrm{ClO}_{4}\right)_{2}=4 \mathrm{SiO}_{2}+\mathrm{CaCl}_{2}
$$

тепловой эффект $Q=8.2 \mathrm{MJ} / \mathrm{kg}$. Данное значение очень хорошо совпадает с экспериментально (в калориметрической бомбе) полученными значениями теплового эффекта $Q=8.6-8.8 \mathrm{MJ} / \mathrm{kg}$, которые приводятся в [13].

Для реакции $\mathrm{Si}+\mathrm{NaClO}_{4}=\mathrm{SiO}_{2}+\mathrm{NaCl}+\mathrm{O}_{2}$ тепловой эффект $Q=6.2 \mathrm{MJ} / \mathrm{kg}$. Для стехиометрической реакции $4 \mathrm{Si}+2 \mathrm{NaClO}_{4}=4 \mathrm{SiO}_{2}+2 \mathrm{NaCl}-Q=10.3 \mathrm{MJ} / \mathrm{kg}$ и, наконец, для реакции $3 \mathrm{Si}+2 \mathrm{NaClO}_{4}=3 \mathrm{SiO}_{2}+$ $+3 \mathrm{NaCl}+\mathrm{O}_{2}-Q=8.4 \mathrm{MJ} / \mathrm{kg}$. Таким образом, расчеты показывают, что ЭНК с перхлоратом натрия более эффективен, чем ЭНК с перхлоратом кальция.

Можно отметить, что теплота взрыва для октола (октоген 75\%, ТНТ 25\%) $Q=5.2 \mathrm{MJ} / \mathrm{kg}$, для PBXW-115 $Q=8.5 \mathrm{MJ} / \mathrm{kg}$, для гексогена $-Q=5.77 \mathrm{MJ} / \mathrm{kg}$, для октогена $Q=5.85 \mathrm{MJ} / \mathrm{kg}$ (все данные приведены в $[18,25]$ ), т. е. ЭНК на основе нанопористого кремния и перхлората кальция превосходит по теплоте взрыва указанные бризантные BB.

\section{Выводы}

1. Из представленного краткого обзора работ, посвященных энергонасыщенным композитам на основе нанопористого кремния в качестве горючего с различными окислителями, следует, что такие композиты интенсивно исследуются и разрабатываются в большинстве стран с развитой инфраструктурой создания и применения ВВ.

2. Проведенные сравнительные исследования ВВ на основе нанопористого кремния и перхлората кальция показали, что данное ВВ по энергетическим параметрам как минимум не хуже традиционных инициирующих и бризантных ВВ.

3. Энергонасыщенные композиты на основе нанопористого кремния в сочетании с различными окислителями, не содержащими токсичные вещества, в перспективе могут быть рекомендованы в качестве альтернативы традиционным ИВВ.

Работа выполнена при поддержке РФФИ, грант № 16-29-01085 офи_м. 


\section{Список литературы}

[1] Uhlir A. // Bell Sys. Tech. J. 1956. Vol. 35. P. 333-338.

[2] Ксенофонтова О.И., Васин А.В., Егоров В.В., Бобыль А.В., Солдатенков Ф.Ю., Теруков Е.И., Улин В.П., Улин Н.В., Киселев О.И. // ЖТФ. 2014. Т. 84. Вып. 1. С. 67-78.

[3] Зимин С.П. // Соросовский образовательный журнал. 2004. T. 8. № 1. C. 101-107.

[4] Лазарук С.К., Долбик А.В., Жагиро П.В., Лабунов В.А., Борисенко В.Е. // ФТП. 2005. Т. 39. Вып. 8. С. 917-919.

[5] Ilyushin M., Shugalei I., Sudurikov A. High-energy metal complexes: Synthesis, Properties, Applications. Saarbrucken: Lambert Academic Publishing, 2017. 156 p.

[6] Matyáš R., Pachman J. Primary Explosives. Heidelberg: Springer, 2013. 338 p.

[7] Авцын А.П., Жаворонков А.А., Риш М.А., Строчкова Л.С. Микроэлементы человека. М.: Медицина, 1991. $496 \mathrm{c.}$

[8] Mc Cord P., Yau S.L., Bard A.J. // Science. 1992. Vol. 257. P. $68-69$.

[9] Kovalev D., Timoshenko V.Y., Künzner N., Gross E., Koch F. // Phys. Rev. Lett. 2001. Vol. 87. N 6. P. 068301/1-068301/4.

[10] Bartuch H., Clément D., Kovalev D., Laucht H. // Proc. of the $7^{\text {th }}$ International Symposium and Exhibition on Sophisticated Car Occupant Safety Systems. Karlsruhe, Germany, 2004. P. 2-17.

[11] Bezuidenhout H.C., Mukhopadhyay S. // Int. J. Basic Appl. Sci. 2013. N 2 (4). P. 381-386.

[12] Bezuidenhout H.C., Mukhopadhyay S. // Int. J. Appl. Eng. Res. 2016. Vol. 11. N 11. P. 10465-10471.

[13] Михайлов Ю.М., Гаранин В.А., Ганин Ю.В., Гончаров Т.К., Ганина Л.В., Зегря Г.Г. // Изв. РАН. Сер. хим. 2016. Вып. 8. C. 2400-2404.

[14] Гусейнов Ш.Л., Федоров С.Г. Нанопорошки алюминия, бора, боридов алюминия и кремния в высокоэнергетических материалах. М.: Торус Пресс, 2015. 256 с.

[15] Abraham A., Nicholas W., Piekiel N.W., Christopher J., Morris C.J., Dreizin E.L. // Propell. Explos. Pyrot. 2016. Vol. 41. P. 179-188.

[16] Hofmann A., Laucht $H$., Kovalev $D$. et al. Explosive composition and its use. U.S. Patent N 6984274, 2006.

[17] Diener J., Gross E., Kunzer N. et al. Nanostructured reactive substance and process for producing the same. U.S. Patent N 6803244, 2004.

[18] Физика взрыва. Т. 1. / Под ред. Л.П. Орленко. М.: Физматлит, 2002. $832 \mathrm{c}$.

[19] du Plessis M. // Phys. Stat. Sol. C. 2009. Vol. 6. N 7. P. $1763-1768$.

[20] du Plessis M. // Propell. Explos. Pyrot. 2014. Vol. 39. P. $348-364$.

[21] Oyler K.D., Cheng G., Mehta N., Redner P., Kapoor D. Green explosives: potential replacements for lead azide and other toxic detonator and primer constituents [Электронный ресурс] Режим доступа: https://ru.scribd.com/document/84839435/Green-Explosives

[22] Subramanian S., Tiegs T., Limaye S., Kapoor D., Redner P. // Proc. of the $26^{\text {th }}$ Army Sci. Conf. Orlando, USA, 2008. MP-08: 1-7.

[23] Handbook of Porous Silicon / Ed. by L. Canham. Springer, 2017. P. $1-9$.

[24] Кузнецов А.В., Савенков Г.Г., Брагов А.М., Константинов А.Ю. // Проблемы прочности и пластичности. 2016. T. 78. № 2. C. 119-128.

[25] Физика взрыва. Т. 2. / Под ред. Л.П. Орленко. М.: Физматлит, 2002. $656 \mathrm{c}$. 